\title{
Analysis of the correlation between p53 and bcl-2 expression with staging and prognosis of the colorectal adenocarcinoma ${ }^{1}$
}

\author{
Análise da correlação entre a expressão da p53 e do bcl-2 com o estadiamento e o \\ prognóstico do adenocarcinoma colorretal
}

\author{
Suzana Angelica Silva Lustosa ${ }^{2}$, Angela Logullo ${ }^{3}$, Ricardo Artigiani ${ }^{3}$, Sarhan Sydney Saad ${ }^{4}$, Alberto Goldenberg $^{4}$, \\ Delcio Matos ${ }^{5}$ \\ 1. Surgical Gastroenterology and Pathology Departments, Federal University of São Paulo - Escola Paulista de Medicina (UNIFESP-EPM). \\ São Paulo, Brazil. \\ 2. Assistant Professor at UniFOA - Centro Universitário de Volta Redonda. Rio de Janeiro, Brazil. \\ 3. Assistant Professor in Pathology Department, UNIFESP-EPM. São Paulo, Brazil. \\ 4. Associate Professor in Surgical Gastroenterology Department, UNIFESP-EPM. São Paulo, Brazil. \\ 5. Associate Professor and Dean of Postgraduate Studies in Surgical Gastroenterology Department, UNIFESP-EPM. São Paulo, Brazil.
}

\begin{abstract}
Purpose: To analyze the correlation between p53 and bcl-2 expression and colorectal adenocarcinoma staging and prognosis. Methods: This was a retrospective series of 125 colorectal adenocarcinoma patients (67 women and 58 men; ages 30-87 years) who underwent surgery with curative intent. The mean follow-up was 28.5 months (range: 2-96 months). TNM staging, tumor recurrence, survival and cancer-related mortality were analyzed. Immunoreactivity was evaluated using DO7 (Dako) for p53 and K492 (Dako) for bcl-2. Tumors with accumulation of staining for cytoplasmic bcl-2 or nuclear p53 in more than $10 \%$ of cells were considered positive. Statistical analysis utilized Pearson chi-squared, log-rank and Wilcoxon tests, and Kaplan-Meier survival estimation (significance level: p<0.05). Results: p53+ was found in 11.8\% (14/118), bcl-2+ in 50\% (58/116) and associated p53+/bcl-2+ in 6.4\% (7/109) of the tumors. There was no significant correlation between expression of these biomarkers and TNM I, II, III and IV staging ( $\mathrm{p}=0.385$ for $\mathrm{p} 53$; $\mathrm{p}=0.461$ for bcl-2). For tumor recurrence, p53+ was found in 9.5\% (2/21), bcl-2+ in 50\% (11/22), and associated p53+/bcl-2+ in 5.2\% (1/19) of the tumors ( $\mathrm{p}=0.714$, $\mathrm{p}=1.000$ and $\mathrm{p}=0.960$, respectively). For survival analysis, p53+: 57 months (45.0-68.0), bcl-2+: 78 (37.0-89.0), and p53+/bcl2+: 62 (56.0-68.0) ( $\mathrm{p}=0.319)$. For cancer-related mortality, p53+: 8.3\% (3/36), bcl-2+: 47.2\% (17/36), and p53+/bcl-2+: 5.9\% (2/ 36) of the patients ( $\mathrm{p}=0.432, \mathrm{p}=0.688$ and $\mathrm{p}=0.907$, respectively). Conclusion: No correlation was found between tumor expression of p53 and bcl-2 and the TNM staging, recurrence, survival and cancer-related mortality in colorectal adenocarcinoma.
\end{abstract}

Key words: Colorectal Neoplasms. Tumor Markers, Biological. Neoplasm Staging. Prognosis.

\begin{abstract}
RESUMO
Objetivo: Analisar a correlação entre a expressão da p53 e do bcl-2 com o estadiamento e prognóstico do adenocarcinoma colorretal. Métodos: Foi realizado o estudo de uma série retrospectiva de 125 doentes com adenocarcinoma colorretal (67 mulheres e 58 homens; 30 a 87 anos de idade), que se submeteram ao tratamento cirúrgico com intenção curativa. O tempo médio de seguimento foi de 28,5 meses (variação de 2 a 96 meses). O estadiamento TNM, a recidiva tumoral, a sobrevida e a mortalidade relacionada com o câncer foram analisados. A reação imunohistoquímica utilizada foi o DO\& (Dako) para o p53 e o K492 (Dako) para o bcl-2. Tumores com intensidade de coloração citoplásmica para o bcl-2 e nuclear para o p53, acima de $10 \%$ de células foram considerados positivos. A análise estatística utilizada foi o teste qui-quadrado de Pearson, log-rank, Wilcoxon e estimativa de sobrevida de Kaplan-Meier (nível de significância : p<0,05). Resultados: p53+ foi encontrado em 11.8\% (14/118), bcl-2+ em 50\% (58/116) e associados p53+/bcl-2+ em 6.4\% (7/109) dos tumores. Não foi encontrado correlação significante entre a expressão tumoral destes marcadores e o estadiamento TNM I, II, III e IV ( $p=0.385$ para a $553 ; p=0.461$ para o bcl-2). Na recidiva tumoral, p53+ foi encontrado em 9.5\% (2/21), bcl-2+ em 50\% (11/22), e $553+/ b c l-2+$ associados em 5.2\% (1/19) dos tumores ( $p=0.714, p=1.000$ e $p=0.960$, respectivamente). Na análise de sobrevida, p53+: 57 meses (45.0-68.0), bcl-2+: 78 (37.0-89.0), e p53+/bcl-2+: 62 (56.0-68.0) (p=0.319). Para mortalidade relacionada com câncer, p53+: 8.3\% (3/36), bcl-2+: 47.2\% (17/36), e p53+/bcl-2+: 5.9\% (2/36) dos pacientes (p=0.432, $\mathrm{p}=0.688$ and $\mathrm{p}=0.907$, respectivamente). Conclusão: Nenhuma correlação significante foi encontrada entre a expressão tumoral da p53 e do bcl-2 com o estadiamento TNM, recidiva, sobrevida e mortalidade relacionada com câncer.
\end{abstract}

Descritores: Neoplasias Colorretais. Marcadores Biológicos de Tumor. Estadiamento de Neoplasias. Prognóstico. 


\section{Introduction}

Colorectal cancer is a frequent cause of morbidity and mortality and its prognosis is mainly based upon histopathological staging. However, different clinical outcomes are seen within each pathological stage. Thus, the need for identifying better prognostic markers is easily recognized. The search for new prognostic parameters is a widely prevalent activity undertaken by pathologists and indeed, for many, it seems to represent a form of Holy Grail ${ }^{1}$. Despite great progress in the knowledge of the molecular mechanism of cancer development and tumor progression, very few biomarkers have been identified as independent prognostic factors and none of them is used in 'routine' practice. A number of studies have shown that, for colorectal adenocarcinoma, a biological profile based on combined evaluation of these biomarkers may be useful for identifying high-risk patients for enrollment in adjuvant treatment ${ }^{2,3,4}$. In general, the currently available data on the correlation between biomarkers and prognosis for colorectal cancer are very often controversial. Carcinogenesis and even the progression of the tumor seem to depend upon a controlled balance between cell proliferation and cell death in the normal colorectal mucosa. Two of the oncogenes implicated in this process are $\mathrm{p} 53$ and bcl-2, which seem to play a very important role in apoptosis. Mutation in the $\mathrm{p} 53$ gene gives rise to an abnormal protein that accumulates in the nucleus, thus allowing its detection by immunohistochemistry ${ }^{6}$. This mutation leads to a reduction in the capacity to undergo apoptotic cell death, and it could be an important step in the development of neoplasia. Over the last ten years, a very interesting field of study has emerged as a result of investigations into the hypothesis that the p53 tumor suppressor gene might show prognostic correlation with cancer. Thus, a plethora of information has been provided, but mostly without clinical significance. In spite of extensive study of bcl-2 regarding hematopoietic malignancies, relatively few data are available on it in relation to epitheliumderived tumors ${ }^{3}$. bcl-2 is an intracellular membrane protein that is capable of inhibiting apoptosis. Some studies have shown that bcl-2 protein prolongs cell survival by blocking programmed cell deaths. Controversial results have been reported regarding the importance of bcl-2 as a prognostic factor in colorectal cancer $r^{5,7,8,9,10}$. Both the tumor suppressor gene p53 and the bcl-2 protein take part in the biological cycle cell, and alterations to these genes are probably related to oncogenesis and evolution of the disease. In the present study we evaluated the potential prognostic correlation of these biomarkers, separately and in association, and also their relationship with pathological stages.

\section{Methods}

A retrospective series of 125 consecutive colorectal adenocarcinoma patients admitted from December 1993 to March 2000 was collected from the files of Hospital Sao Paulo, Federal University of São Paulo - Escola Paulista de Medicina (UNIFESP-EPM). The series consisted of 67 women and 58 men with ages ranging from 30 to 87 years. The mean follow-up was 28.5 months, ranging from 2 months to 96 months.
All patients underwent surgery with curative intent. The outcome was curative for 98 patients (78,4\%), while it was palliative for the remaining 27 (21,6\%). The resection was regarded as curative when the surgeon was able to identify that no tumor was left behind and when there was histopathological evidence of a clear surgical margin on the surgical specimen. No patient underwent neoadjuvant therapy. The was focused specifically on local and distant recurrence, survival analysis and cancer-related mortality. Tumor tissues were pathologically staged according to the TNM classification, as follows: 21 patients $(16,8 \%)$ were classified as stage I, 41 (32,8\%) as stage II, 28 (22,4\%) as stage III, and 35 (28\%) as stage IV.

TABLE 1 - Colorectal adenocarcinoma patients characteristics.

\begin{tabular}{ll}
\hline & $\mathrm{n}=125$ \\
\hline Sex ratio (M:F) & $58 / 67$ \\
Mean age (years) & $63,4(30 / 87)$ \\
Tumour site & \\
Right colon & $33(26,4 \%)$ \\
Left colon & $27(21,6 \%)$ \\
Rectum & $65(52,0 \%)$ \\
Residual disease status & \\
None & $98(78,4 \%)$ \\
Local & $27(21,6 \%)$ \\
Mean follow-up time(months) & $28,5(2 / 96)$ \\
Cancer-related mortality & $22(22,4 \%)$ \\
Recurrence & \\
Local & $24(24,4 \%)$ \\
Metastatic & 0 \\
TNM Stage & \\
I & $21(16,8 \%)$ \\
II & $41(32,8 \%)$ \\
\hline III & $28(22,4 \%)$ \\
IV & $35(28,0 \%)$ \\
\hline
\end{tabular}

Formalin-fixed and paraffin-embedded tissue samples of colorectal cancer were cut into 4-mm sections and dried overnight at $60^{\circ} \mathrm{C}$. Representative sections were stained using hematoxylin-eosin prior to immunostaining, to ensure that the slides showed tumor tissue as the regions of interest. All the slides were examined and scored independently by three investigators in blinded fashion, without knowledge of the clinical and histopathological data. Any initial divergences in the reviewers' results were followed by reevaluation in order to reach consensus. Immunoreactivity for the p53 protein was detected by using monoclonal antibody DO7 (Dako, Denmark). Tumors were considered to be positive for p53 when more than $10 \%$ of the cells were stained, excluding areas with faintly stained cells, or positive cells located at the margins of the section or in areas with poor morphology. bcl-2 expression was analyzed by using the K492 kit (Dako, Denmark). Tumors were considered to be positive for bcl- 2 when more than $10 \%$ of the cells accumulated cytoplasmic bcl-2 staining. Tumor cells were only considered positive for bcl-2 when the cytoplasmic 
immunoreaction was strong and homogeneous. In the statistical analysis, the survival curve was estimated by the Kaplan-Meier product-limit method. The log-rank test and chi-squared tests were used to assess differences between subgroups. Cox univariate modeling was used to estimate the relative risk and the confidence limits for each variable. A multivariate Cox proportional hazard model was also produced using stepwise regression. The Wilcoxon test (Breslow version) was used to analyze the degree of significance between variables. Statistical significance was assessed at the $5 \%$ level $(\mathrm{p}<0.05)$.

\section{Results}

The protein p53+ was found in $11.8 \%(14 / 118)$ of the tumors, bcl-2+ in 50\% (58/116), and a combination of p53+ and bcl-2+ in 6.4\% (7/109). No significant correlation was found between biomarker expression and TNM I, II, III and IV staging ( $\mathrm{p}=0.385$ for $\mathrm{p} 53+$; $\mathrm{p}=0.461$ for $\mathrm{bcl}-2+$; and $\mathrm{p}=0.937$ for the association of $\mathrm{p} 53+$ and bcl-2+). The tumor recurrence rate was not associated with $\mathrm{p} 53+(\mathrm{p}=0.714)$, bcl-2+ $(p=1.000)$, and the association of $\mathrm{p} 53+$ and bcl-2+ $(\mathrm{p}=0.960)$. Survival analysis for $\mathrm{p} 53+$ showed a mean of 57 months (range: 45.0 - 68.0); for bcl-2+ it was 78 months (37.0 - 89.0); and for the association of p53+ and bcl-2+, it was 62 months (56.0-68.0) ( $\mathrm{p}=0.319)$. Cancer-related mortality occurred in $\mathrm{p} 53+$ tumors in $83 \%$ of the patients $(3 / 36)(\mathrm{p}=0.432)$; in bcl$2+$ tumors in $47.2 \%$ of the patients $(17 / 36)(\mathrm{p}=0.688)$; and in the association of p53+ and bcl-2+ tumors in $5.9 \%$ of the patients $(2 / 36)(p=0.907)$.

TABLE 2 - Tumour expression of p53, bcl-2 and associated p53/bcl-2.

\begin{tabular}{llll}
\hline & p53 & bcl-2 & p53 and bcl-2 \\
& $\mathrm{n}(\%)$ & n.(\%) & n.(\%) \\
\hline positive & $14(11)$ & $58(50)$ & $11(14,6)$ \\
negative & $104(89)$ & $58(50)$ & $64(85,4)$ \\
\hline Total & $108(100)$ & $116(100)$ & $75(100)$ \\
\hline
\end{tabular}

TABLE 3 - Tumour recurrence and expression of p53, bcl2 and associated p53/bcl-2.

\begin{tabular}{llll}
\hline & p53 & bcl-2 & p53 and bcl-2 \\
& $\mathrm{n}(\%)$ & n.(\%) & n.(\%) \\
\hline positive & $2(9,5)$ & $11(50)$ & $1(5,2)$ \\
negative & $19(90,5)$ & $11(50)$ & $10(52,7)$ \\
\hline Total & $21(100)$ & $22(100)$ & $19(100)$ \\
\hline
\end{tabular}

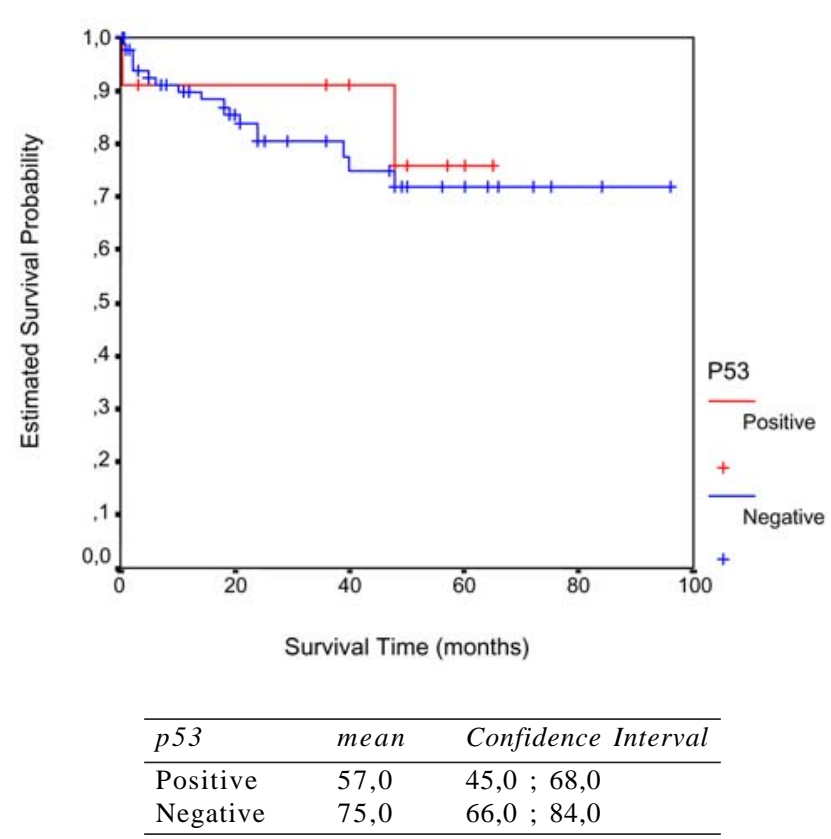

Wilcoxon Test(Breslow version): $\mathrm{p}=0,7258$

FIGURE 1 - Kaplan-Meier curves for cumulative survival in 118 patients with colorectal adenocarcinoma according to p53 status.

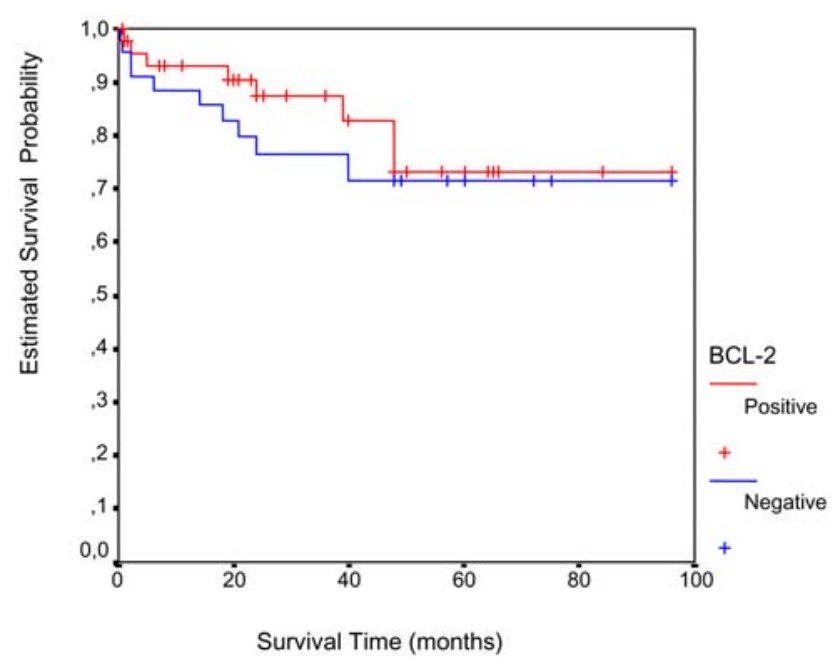

\begin{tabular}{lll}
\hline bcl-2-2 & mean & Confidence interval \\
\hline positive & 78,0 & 37,$0 ; 89,0$ \\
negative & 73,0 & 61,$0 ; 85,0$ \\
\hline & log-rank test: $\mathrm{p}=0,471$
\end{tabular}

FIGURE 2 - Kaplan-Meier curves for cumulative survival in 116 patients with colorectal adenocarcinoma according to bcl-2 status. 


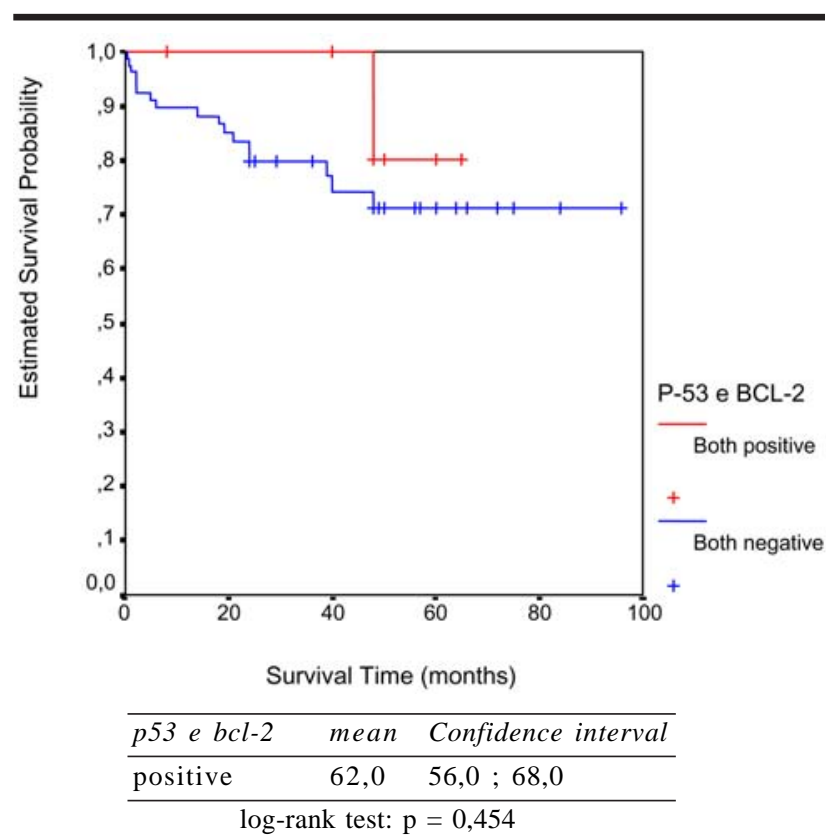

FIGURE 3 - Kaplan-Meier curves for cumulative survival in 11 patients with colorectal adenocarcinoma according to associated p53 and bcl-2 status.

TABLE 4 - p53 tumour expression and TNM staging.

\begin{tabular}{lllll}
\hline $\mathrm{p} 53$ & $\begin{array}{l}\text { TNM I } \\
\mathrm{n}(\%)\end{array}$ & $\begin{array}{l}\text { TNM II } \\
\mathrm{n}(\%)\end{array}$ & $\begin{array}{l}\text { TNM III } \\
\mathrm{n}(\%)\end{array}$ & $\begin{array}{l}\text { TNMIV } \\
\mathrm{n}(\%)\end{array}$ \\
\hline positive & $3(9,0)$ & $4(19,0)$ & $5(16,7)$ & $2(5,8)$ \\
negative & $30(91,0)$ & $17(81,0)$ & $25(83,3)$ & $32(94,2)$ \\
\hline total & $33(100,0)$ & $21(100,0)$ & $30(100,0)$ & $34(100,0)$ \\
\hline \multicolumn{5}{r}{$\mathrm{p}=0,385$} \\
\end{tabular}

TABLE 5 - bcl-2 tumour expression and TNM staging.

\begin{tabular}{lllll}
\hline bcl-2 & $\begin{array}{l}\text { TNM I } \\
\mathrm{n}(\%)\end{array}$ & $\begin{array}{l}\text { TNM II } \\
\mathrm{n}(\%)\end{array}$ & $\begin{array}{l}\text { TNM III } \\
\mathrm{n}(\%)\end{array}$ & $\begin{array}{l}\text { TNMIV } \\
\mathrm{n}(\%)\end{array}$ \\
\hline positive & $14(50,0)$ & $9(39,0)$ & $18(60,0)$ & $16(45,7)$ \\
negative & $14(50,0)$ & $14(61,0)$ & $12(40,0)$ & $19(54,3)$ \\
\hline total & $28(100,0)$ & $23(100,0)$ & $30(100,0)$ & $35(100,0)$ \\
\hline \multicolumn{5}{c}{$\mathrm{p}=0,476$} \\
\end{tabular}

TABLE 6 - Associated p53 and bcl-2 tumour expression with TNM staging.

\begin{tabular}{lllll}
\hline p 53 and bcl-2 & TNM I & TNM II & TNM III & TNM IV \\
& $n(\%)$ & $n(\%)$ & $n(\%)$ & $n(\%)$ \\
\hline positive & $1(8,4)$ & $1(6,6)$ & $2(16,7)$ & $2(11,8)$ \\
negative & $11(91,6)$ & $14(93,4)$ & $10(83,3)$ & $15(88,2)$ \\
\hline total & $12(100,0)$ & $15(100,0)$ & $12(100,0)$ & $17(100,0)$ \\
\hline \multicolumn{5}{c}{$\mathrm{p}=0,937$}
\end{tabular}

\section{Discussion}

The limitations of histopathological parameters for identifying subgroups among colorectal cancer patients that may benefit from adjuvant therapy are obvious, considering that different outcomes are frequently seen in each pathological stage. Improvement in colorectal cancer therapy can only be achieved if new tumor markers with significant prognostic potential can be identified. There has been an intensive search for such markers, but none of them can be considered to be independent prognostic variables. The histopathological parameter that is most used, the presence of lymph node metastasis, is an example of this $^{11}$. Over the last ten years, a large volume of scientific information has been made available through a huge number of studies. However, the results from these are mostly of no clinical relevance. These studies have mainly focused on biological markers, which have been recognized as key factors in the understanding of the process of oncogenesis. Thus, in spite of the recent progress in defining the molecular mechanism for cancer development, only few individual biomarkers providing prognostic information have been identified $^{12}$. Although Fearon \& Vogelstein put forward a good model for the temporal sequence of the genetic alterations occurring in colorectal tumorigenesis, so far it is not clear whether positive p53 immunoreactivity can identify a subset of tumors with distinct biological behaviour ${ }^{13}$.

It has been reported that the great variation in study methodologies is responsible for the heterogeneity of the results. The patient selection, specimen processing, immunohistochemical techniques, data interpretation and statistical analysis have been so variable that it makes the interpretation of the published literature at best difficult ${ }^{1}$.

In our study we used formalin-fixed paraffin-embedded tissues, and the sections were microwave processed before being incubated with the primary antibody. This type of treatment has been reported to be an excellent antigen retrieval method for $\mathrm{p} 53^{3,14,15}$. In immunohistochemical studies, a threshold must be set for the amount of cells staining, in order to distinguish positive biological samples from negative ones. In our study, the level at which we considered the marker expression to be positive was set on the basis of the majority of cutoff points used in the recent literature. If the threshold is chosen on the basis of the best separation of clinical outcomes, it is obvious that the validity of the study is questionable ${ }^{1}$. On the other hand as, in our study, three examiners analyzed the sections, in a blinded manner and without knowledge of the clinical and pathological data, the possibility of measurement bias may have been decreased. Based on the results from the present study, we are able to say that the $\mathrm{p} 53$ and bcl- 2 proteins seem not to have prognostic potential for patients with colorectal adenocarcinoma. In fact, Dowell and Hall ${ }^{1}$ showed that p53 in particular is only a weak prognostic factor that cannot alone identify a group with such a low risk of recurrence that treatment would not be indicated. According to these authors, while p53 is of undisputed importance in our understanding of oncogenesis and neoplasia, it would seem that the Holy Grail has not yet been found. We could not agree more ${ }^{1}$. There seems to be a very close correlation between the sample size in a study and the probability that p53 is regarded as an independent prognostic variable. Thus, we may need large groups of patients in order to get enough statistical power to demonstrate the significance of this biomarker. This implies that p53 is only a relatively weak prognostic factor ${ }^{1}$. A review of the literature by 
Tollenaar et al. ${ }^{5}$ led to the same conclusion. In the same way, 46 studies that assessed the prognostic value of p53 status, which we obtained from a Medline search between 1995 and 2002, confirmed that there is a strong correlation between the number of cases in the study and the possibility that p53 could be a prognostic factor. A recent and comprehensive review of tumor molecular markers and their prognostic significance concluded that the relevant data are contradictory and that, until further data become available, histopathological parameters such as the $\mathrm{T}$ and $\mathrm{N}$ categories are at present more meaningful ${ }^{17}$. Our results using bcl-2 are in accordance with recent published literature. Thus, we could not find any degree of significance in any of the prognostic parameters studied. Likewise, we were unable to correlate the histopathological findings and TNM categories with bcl-2 expression, on the basis of the proposition that the bcl-2 protein alterations may occur very early in oncogenesis ${ }^{18}$. The combined evaluation of p53 and bcl-2 expression in the tumor was of no value for reaching prognostic significance. We find that there is no reason at all to share in the optimism expressed in the literature regarding the combination of these two markers for making colorectal cancer prognoses. The rationale behind these markers, based on their logical participation in the apoptosis process, does not justify the intensive research into their prognostic significance.

\section{Conclusion}

On the basis of our findings we conclude that p53 and bcl-2 probably have no potential to act as significant parameters in colorectal cancer staging and prognosis.

\section{References}

1. Dowell SP, Hall PA. The p53 tumour supressor gene and tumour prognosis: is there a relationship? Editorial. J Pathol. 1995;177:221-4.

2. Buglioni S, D’Agnano I, Cosimelli M, et al. Evaluation of multiple bio-pathological factors in colorectal adenocarcinomas:independent prognostic role of p53 and bcl2. Int J Cancer. 1999;84:545-52.

3. Pereira H, Silva S, Julião R, et al. Prognostic markers for colorectal cancer: expression of p53 and bcl2. World J Surg. 1997;21:210-3.

4. Schwandner O, Schiedeck THK, Bruch HP, et al. P53 and bcl2 as significant predictors of recurrence and survival in rectal cancer. Eur J Cancer. 2000;36:348-56.
5. Toleenaar RAEM, Krieken JHJM, Slooten HJ et al. Immunohistochemical detection of p53 and bcl-2 in colorectal carcinoma: no evidence for prognostic significance. Br J Cancer. 1998;77:1842-7.

6. Baas IO, Mulder JWR, Offerhaus GJA et al. An evaluation of six antibodies for immunohistochemistry of mutant p53 gene product in archival colorectal neoplasms. J Pathol. 1994;172:5-12.

7. Baretton GB, Diebold J, Christoforis G, et al. Apoptosis and immunohistochemical Bcl-2 expression in colorectal adenomas and carcinomas. Cancer. 1996;77:255-64.

8. Manne U, Myers RB, Moron C, et al. Prognostic significance of Bcl-2 expression and p53 nuclear accumulation in colorectal adenocarcinoma. Int J Cancer. 1997;74:346-58.

9. Oefner D, Riechemann K, Maier $\mathrm{H}$, et al. Immunohistochemically detectable Bcl-2 expression in colorectal carcinoma: correlation with tumor stage and patient survival. Br J Cancer. 1995;72:981-5.

10. Bosari S, Moneghini L, Graziani D, et al. Bcl-2 oncoprotein in colorectal hyperplastic polyps, adenomas and adenocarcinomas. Hum Pathol. 1995;26:534-40.

11. Neland RC, Dent OF, Lytle MNB, et al. Pathologic determinants of survival associated with colorectal cancer with lymph node metastasis. Cancer. 1994;73:2076.

12. Schwandner O, Schiedeck THK, Bruch HP, et al. P53 and bcl-2 as significant predictors of recurrence and survival in rectal cancer. Eur J Cancer. 2000; 36:348-56.

13. Fearon ER and Vogelstein B. A genetic model for colorectal cancer tumorigenisis. Cell. 1990;61:759.

14. Lambkin H, Mothersill C, Kelehan P, et al. Variations in immunohistochemical detection of p53 protein overexpression in cervical carcinomas with different antibodies and methods of detection. J. Pathol. 1994;172:13.

15. Cattoretti G, Pileri S, Becker M, et al. Antigen unmasking on formalin-fixed paraffin-embedded tissue sections. J. Pathol. 1993; 171:83.

16. Toleenaar RAEM, Krieken JHJM, Slooten HJ et al. Immunohistochemical detection of p53 and bcl-2 in colorectal carcinoma: no evidence for prognostic significance. Br J Cancer. 1998;77:1842-7.

17. Klump B, Nehls O, Okech T et al. Molecular lesions in colorectal cancer: impact on prognosis? Original data and review of the literature. Int $\mathrm{J}$ Colorectal Dis. 2004;19:23-42.

18. Bronner MP, Culin C, Ree JC, et al. The Bcl2 protooncogene and the gastrointestinal epithelial tumor progression model. Am J Pathol. 1995;146:20-6.

\begin{tabular}{lr}
\hline Correspondence: & Conflict of interest: none \\
Delcio Matos & Financial source: none \\
Rua Edison, 278/61 & Received: April 12, 2005 \\
04618-031 São Paulo - SP & Review: May 10, 2005 \\
dmatos.cir@epm.br & Accepted: June 14, 2005
\end{tabular}

How to cite this article:

Lustosa SAS, Logullo A, Artigiani R, Saad SS, Goldenberg A, Matos D. Analysis of the correlation between p53 and bcl2 expression with staging and prognosis of the colorectal adenocarcinoma. Acta Cir Bras. [serial on the Internet] 2005 SeptOct;20(5). Available from URL: http://www.scielo.br 